\title{
LA EPIDEMIA DE FIEBRE AMARILLA DE 1870 EN ALICANTE
}

Guillermo Segui Marco

\section{LA FIEBRE AMARILLA EN ALICANTE EN EL AÑO 1870 \\ 1. 1. Los inicios de la epidemia}

Durante los tres últimos meses de 1870 se extendió en la ciudad de Alicante una epidemia de fiebre amarilla. Oficialmente la epidemia no comenzó en la ciudad hasta el día 4 de octubre en que se declaró sucio su puerto a todos los efectos y por consiguiente cerrado para la nevegación y el comercio por haberse producido en Alicante una "enfermedad que, por fortuna, se ha presentado en ésta con carácter benigno ${ }^{1}{ }^{1}$ incluso una semana antes de que se publicara esta circular, el Gobierno Civil negaba la evidencia de toda epidemia con estas palabras: "Falsas alarmas de todo punto injustificadas, nacidas las más de las veces del pánico (...); noticias circuladas por algunas personas, que, sin darlas crédito, no se oponen a que encuentren eco en la opinión pública, han esparcido por la mayor parte de los pueblos de esta provincia el alarmante rumor de que algunos casos de fiebre amarilla habían tenido lugar en esta capital, amenazando envolverla en los horrores de una epidemia, de la que, Gracias a Dios, nos vemos completamente libres". 2 Por

1 B. O. P., Circular de Sanidad núm. 239, Diario "La Revolución", 6 de octubre de 1870 .

2 B. O. P., Circular núm. 233, de 28 de septiembre de 1870. 
desgracia estas palabras no se ajustaban a la realidad, ya que el día 13 de septiembre de aquel año ya se habían producido las dos primeras defunciones a consecuencia de la fiebre amarilla y la enfermedad amenazaba con extenderse, pues, según Manero, el Dr. Remigio Sebastiá, que atendió a las mujeres fallecidas dio parte al subdelegado de Medicina y éste al gobernador civil y "todos entendieron ver el desastroso efecto del mal de Siam, pero para evitar los perjuicios que se originarían al comercio de la plaza y el terrible pánico que se fomentaría, declararon que murieron a consecuencia de fiebres perniciosas, confiando en que el contagio tal vez se limitaría a aquellas dos mujeres». ${ }^{3}$

De todos modos, la epidemia de tifus icteroides comienza a extenderse a partir de Barcelona. Hay que resaltar aquí que en fechas anteriores al decreto de declaración de puerto sucio en Barcelona, todos los buques se recibían en ésta sin las formalidades de policía sanitaria y según Manero uen todo este tiempo hasta el 30 de septiembre se desembarcaron en nuestro puerto más de doscientos bultos consignados a diferentes comerciantes", ${ }^{4}$ siendo lo más curioso del caso que algunos de ellos procedían directamente del vapor Maria, vehículo originario de la infección en Barcelona, hecho que no habla precisamente a favor de las autoridades sanitarias, que como vemos no tomarán medidas eficaces hasta muy adentrada la crisis. Al declararse sucio el puerto barcelonés, se estableció un lazareto de expurgo y ventilación donde permanecian los efectos procedentes de tal punto para su desinfección, inconveniente que los viajeros y comerciantes solventaban mediante el transporte a través del ferrocarril, donde eran recibidos sin escrúpulos, hecho que Manero da como origen de la importancia de la enfermedad al escribir "nuestra política sanitaria sería más plausible si lejos de limitarse a la higiene naval, se hiciera extensiva a las importaciones por tierra, estableciendo nuevas cuarentenas y cordones sanitarios. Este descuido, de fatal recuerdo para Alicante, dio margen en 1870 a una desolación, harto fecundo en víctimas". ${ }^{5}$ Entre las

3 MANero, E., "La fiebre amarilla en Alicante en el año 1870", Alicante 1879, p. 12.

4 Manero, E., Op. cit.

5 Manero, E., Op. cit., p. 10. 
personas que, por este medio, llegaban a Alicante, se encontraban dos mujeres, de 80 y 40 años respectivamente, que murieron a los tres días presentando "vómitos de materiales negruzcos, postración y abatimiento hasta el colapso, frío intenso y color marcadamente ictérico en la piel". ${ }^{6}$ En este momento es cuando se da parte a Gobernación de tal hecho que es acallado "para evitar los perjuicios que se originarían al comercio...". Estas previsiones no se cumplirian ya que del 10 al 15 de septiembre ya habian sido invadidas otras muchas personas: una mujer de dieciocho años que vivía en una barraca del Postiguet, contigua a la calle donde murieron las anteriores, pero que al hallarse menstruando, sus familiares atribuyeron el mal a la supresión del flujo a consecuencia de haberse bañado en el mar, no llamando al médico hasta el día 18 en que murió la enferma; un comerciante de loza, domiciliado en la calle de San Fernando, enfermó con toda su familia de la que fallecieron esposa y dos hijas; otra mujer, domiciliada en San Fernando, 5, a la sazón enferma de seirro ovárico, murió uno de estos dias; cuatro días después de haberse producido este óbito una familia vecina también pagó su tributo, al fallecer cuatro personas de una vivienda de cinco. Basten estos ejemplos para mostrar que en los días que siguieron a los primeros fallecimientos debidos al tifus icteroides, éste se había extendido por una zona perfectamente delimitada de la ciudad: por un lado en las inmediaciones del Postiguet y por otro las calles vecinas de las citadas San Fernando y San Francisco, todas centro de la población y residencia del comercio. Manero cita las siguientes: Calatrava, Princesa, Bilbao, Mayor, Bailén, Méndez Núñez y Plazas de la Constitución y de la Libertad. ${ }^{7}$ De la misma forma, todos los afectados presentaban idénticos síntomas tomados por distintos facultativos: "frio inicial, cefalgia, dolores lumbares, fiebre, vómitos, cámaras melánicas y color de piel ictéricon. ${ }^{8}$ Podemos hablar, pues, con propiedad de la existencia de una epidemia, aún antes de que ésta sea reconocida públicamente en ámbitos gubernamentales. En todo este tiempo se dieron numerosas invasiones, de

8 Manero, E., Op. cit., p. 12. 
las que, según Manero, no se dio cuenta oficial al expedir los médicos certificados de defunción que falseaban la verdadera naturaleza del mal, exponiendo como causa de los fallecimientos enfermedades diversas como fiebres tifoideas, biliosas, tifus europeo, gastro hepatitis, ictericia, hemorragia, etc. Incapaces ya de mantener oculta la situación, el 4 de octubre se da cuenta de nueve invasiones y tres muertes, y el mismo día se declara sucio el puerto como también ocurre con otros puntos del levante peninsular, principalmente en Barcelona, Palma de MaIlorca y Valencia.

\section{2. Los efectos demográficos}

A pesar de que se ha intentado localizar los documentos originales que las juntas de sanidad emitían para dar cuenta de la incidencia y evolución de la crisis epidémica, o los resúmenes estadísticos efectuados por el mismo organismo una vez concluida la catástrofe, esto no ha sido posible ya que en la actual Delegación Provincial de Sanidad desconocen la existencia de dichas fuentes; de la misma forma, en los archivos de la Diputación Provincial de Alicante aducen ignorancia sobre la permanencia de dichos fondos en su archivo, dependencia que no dispone de catalogación sobre sus existencias, según nos hizo saber la funcionaria que se encuentra a su frente. Por esta razón, nos vemos privados de unos textos que hubieran aportado mucha luz a nuestra investigación ya que las cifras que poseemos referentes a los efectos demográficos de la epidemia, al proceder de fuentes distintas, difieren notablemente.

Para cuantificar las consecuencias demográficas de la epidemia, hemos acudido nuevamente a los libros de defunciones existentes en la Catedral de San Nicolás y en la Parroquia de Santa María, únicas iglesias de la época con potestad para registrar dichas partidas, (que tendrían como utilidad práctica el facilitar el recuento de enterramientos efectuados a través de las parroquias). Por otro lado, Manero Mollá en las obras anteriormente citadas introduce unos resúmenes estadísticos de gran utilidad sobre invasiones y defunciones con expresión de edades y sexos, además de cuadros con noticias de la evolución de la en- 
fermedad y de observaciones meteorológicas, al ser las condiciones del tiempo tan influyentes en el curso de la epidemia.

El número de defunciones anotadas en las dos parroquias, y que nosotros hemos sumado por cohortes de edad y sexo, difieren en 807 de las cifras aportadas por Manero, para las que, por desgracia, no cita procedencia, no concordando además con las cifras impresas en el diario La Revolución, que publica una sección sobre el Estado Sanitario de la población entre el 8 de octubre hasta el 16 de diciembre de 1870, faltando, por consiguiente, los datos referidos a los veinte primeros días siguientes de octubre, cuatro de noviembre y uno de diciembre. ${ }^{9}$

Nos encontramos, pues, ante tres fuentes que ofrecen diferentes cifras entre sí, aunque su finalidad sea distinta: información puntual y diaria para la ciudadanía por parte de la Junta de Sanidad utilizando como medio las páginas de un diario; efectuar un trabajo científico en el caso de Manero; los libros de difuntos de larga tradición en lo referente a las parroquias.

Para nuestro trabajo nos ceñiremos a las dos últimas, ya que al omitirse en "La Revolución" las cifras referidas a los veinte primeros días de la catástrofe y algunos de su posterior desarrollo, hemos creído conveniente no añadir más confusión a algo, ya de por sí suficientemente oscuro.

Las cuantificaciones que ofrece Manero, por otra parte, nos parecen más creíbles que los datos registrados en los libros de difuntos de las parroquias $y$, aunque no cite su procedencia, creemos que estos datos pueden proceder de los resúmenes, de paradero desconocido en la actualidad, que las Juntas de Sanidad elaboraron una vez concluida la epidémia, aunque hemos encontrado un resumen estadístico en las páginas del diario republicano-federal que ratifican nuestras consideraciones favorables a las cifras aportadas por Evaristo Manero. ${ }^{10}$ La expresión

9 Diario "La Revolución», núm. 8 de octubre y 16 de diciembre.

10 Diario "La Revolución", comunicado de la Junta de Sanidad sobre el "Estado de la población durante la epidemian. Los datos desglosados son los siguientes: La ciudad reducida a 9.500 habitantes.

\begin{tabular}{lrllr}
\multicolumn{1}{r}{ INVASIONES } & & & \multicolumn{2}{c}{ DEFUNCIONES } \\
Hombres & 3.800 & & Hombres & 1.033 \\
Mujeres & 984 & & Mujeres & 207 \\
Niños/as & 464 & & Niños/as & 62 \\
\cline { 1 - 2 } \cline { 1 - 1 } Total & 5.248 & & Total & 1.302
\end{tabular}


numérica de estos datos no aparece redondeada y provienen de un testigo directo de los acontecimientos que publicó sus obras nueve y trece años, respectivamente, después de producirse los hechos.

En primer lugar, se nos ofrece una visión de las invasiones con expresión del sexo a partir de los diez años, sumando la cantidad de invadidos entre niños y niñas como sigue:

\begin{tabular}{|c|c|}
\hline INVADIDOS: & 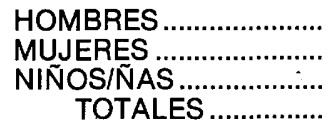 \\
\hline
\end{tabular}

Comoquiera que del número de infectados solamente poseemos estos datos, pasaremos a analizarlos a continuación, en la certeza de su fiabilidad. Lo primero que nos debe llamar la atención es fijar la mortalidad especifica, esto es, la relación existente entre la población afectada por el contagio y la población total, expresada en tanto por mil, lo cual nos da la medida de la importancia de la epidemia.

El problema es establecer para dicho cálculo el volumen de la población total de la ciudad expuesta al contagio, pues si en un apartado anterior dijimos que Alicante tenía una población total de 29.550 habitantes, la epidemia sólo tiene incidencia, al parecer, en el centro de la población, excluyendo sus partidas rurales; considerando este matiz, la población en riesgo potencial quedaria reducida a los 21.719 habitantes que residian en el núcleo urbano propiamente dicho; si además consideramos la emigración que se produjo huyendo del contagio, y que dejó reducido el vecindario a unos 12.500 habitantes, ${ }^{12}$ el volumen de población teóricamente expuesta al contagio disminuyó notablemente. Consideraremos estas dos últimas cifras, aunque la segunda no es exacta y se debe al cálculo de un testigo:

MANERo, E., "La fiebre amarilla...", Alicante, 1879, p. 30. 


\begin{tabular}{lccc} 
& $\begin{array}{c}\text { Población } \\
\text { Total }\end{array}$ & $\begin{array}{c}\text { Población } \\
\text { Afectada }\end{array}$ & $\begin{array}{c}\text { Indice } \\
\text { Morbilidad }\end{array}$ \\
$\begin{array}{lccc}\text { Casco Urbano } \\
\text { Casco Urbano- }\end{array}$ & 21.719 & 5.353 & $246 \% 0$ \\
$\begin{array}{l}\text { Emigración } \\
\text { Fuentes: Padrón Municipal }\end{array}$ & 12.500 & 5.353 & $428 \%$ \\
\hline
\end{tabular}

En el caso de que nos atengamos a la $P$. T. del casco urbano, sin descontar el éxodo de individuos que se lo podían permitir tenemos que el tifus icteroides afectó casi a un cuarto de la población $246 \%$, más de la mitad efectivos masculinos y si tenemos en cuenta que la huida de quienes tuvieron medios para ello redujo a sólo 12.500 el número de residentes, la morbilidad se aproxima al $500 \%$ (428\%o), lo que supone que casi la mitad de la población que permaneció en Alicante en esos momentos fue afectada, en distinto grado, por la efermedad. Como vemos, en uno y otro caso, nos hallamos ante una morbilidad considerable, que afectó fundamentalmente a los hombres pertenecientes a las clases menos favorecidas del vecindario, dándose una vez más, el fenómeno recurrente de discriminación social que pone en marcha la enfermedad desde las grandes epidemias del siglo XIV. ${ }^{13}$ Veamos a continuación las cifras de defunciones.

(Cuadros y gráficas 1 y 2).

Siguiendo a E. Manero, si las defunciones son 1.380 en total, el índice de fallecimientos con respecto a contagios sería del $258 \%$, es decir, que fallecían la cuarta parte de los infectados; tomando la P. T. del casco urbano observamos que la mortalidad epidémica ascendía al $63,54 \%-46,70 \%$ para la totalidad del municipio - y ello sin contar la mortalidad ordinaria del mismo período, la cifra es, pues, muy considerable para una epidemia que se desarrolla en el último tercio del siglo XIX y en un año en que la tasa de mortalidad bruta para el conjunto del país se sitúa en un $30,6 \% .{ }^{14} \mathrm{Si}$ atendemos, por otra parte, a las cifras

13 Baehrel, R., "La haine de classes en temps d'epidémie", Annales E. S. C., (1952), pp. 351-360.

14 NADAL, J., "La población española», Barcelona, 1973, p. 145. 
parroquiales, éstas difieren notablemente de las suministradas por Manero, que cobra mayor fiabilidad. Efectuando la adición de enterramientos que se llevan a cabo á partir de las dos parroquias alicantinas, aparecen 573 fallecidos a consecuencia de la fiebre amarilla entre los meses de septiembre y diciembre de 1870 , con lo que el índice de mortalidad a causa de esta enfermedad difiere notablemente con el que se deriva de los datos suministrados por el médico, ya que éste se situaría en un $26,38 \%(19,39 \%$ para la totalidad del municipio que como hemos visto se aproximan a los publicados por las Juntas de Sanidad en "La Revolución" el 1 de diciembre de 1870) frente al $63,54 \%$ (46,70\% para el total del censo). De todas formas, ya hemos dicho que consideramos erróneos estos índices, obtenidos a partir de los datos parroquiales y además por dos razones fundamentales: la primera se deriva de que en los primeros momentos de la epidemia, cuando aún no se había declarado sucio el puerto, es decir, durante unos veinte días, los facultativos médicos expedían certificados de defunción que ocultaban la auténtica naturaleza de los óbitos, cuando éstos se producian a consecuencia del tifus icteroides, según denuncia el propio Manero; pese a ello la adición de estos registros con los que en fechas posteriores sí señalan como causa la enfermedad epidémica no darían como resultado, ni de lejos, las cifras reflejadas por Manero. El segundo razonamiento es, sencillamente, que no se inscribian todas las defunciones, a pesar que desde el Ayuntamiento de la ciudad se escribió al párroco de San Nicolás, remitiéndole el estado de los fallecidos en el Hospital Provincial para extender dichas partidas en los libros parroquiales, ${ }^{15}$ inscripciones que, nos consta, no fueron efectuadas por los encargados del registro parroquial. Hemos de tener en cuenta, además, que en un período de mortalidad extraordinariamente excepcional (en el periodo de estado de la enfermedad, Manero cita 42 defunciones diarias) ${ }^{16}$ no todos los enterramientos serán efectuados a partir de las iglesias, ni habría tiempo material para hacer todos los oficios religiosos - aun así en los días de mayor mortalidad

15

16

Registro Gral. de Salidas de documentos del Ayuntamiento de Alicante, oficio 1.173, 17 de diciembre de 1870.

MANERo, E., "La fiebre amarilla...", Alicante, 1879, p. 29. 
se realizaban entre diez y veinte oficios - ni infraestructura para Ilevarlos a cabo, ya que existían, según recuento efectuado en el Padrón Municipal 30 eclesiásticos en todo el casco urbano, aunque no todos dependían de las parroquias antes citadas.

Por ello, si en épocas consideradas como normales, sin altas cifras de mortalidad, los libros parroquiales de defunciones son un excelente material de trabajo para el investigador, hay que considerar, cuando nos encontramos con años de mortalidad excesiva, sobre todo en una crisis epidémica, un considerable índice de ocultación. De cualquier manera, en períodos protoestadísticos ${ }^{17}$ los libros eclesiales constituyen un excelente indicador para el estudio demográfico aún más en un país como España, donde era innegable el cumplimiento estricto de los sacramentos del bautismo y del matrimonio, y del deseo de ser enterrado en suelo sagrado.

En cualquier caso, también se añadirán a este estudio particular todos los datos extraídos de estos registros ya que en algunos aspectos, y salvando distancias, presentan similitudes con los aportados por Manero. Si descendemos a analizar estos datos, encontramos que todas las edades y ambos sexos sufrieron los efectos del tifus icteroides, aunque éstos se manifiestan con mucha mayor virulencia en los efectivos masculinos en general; $81,60 \%$ las defunciones totales, según las cifras de Manero, $60,94 \%$ si tenemos en cuenta los datos extraídos de las parroquias, y en los hombres de edad adulta en particular, sobre todo de edades que oscilan entre los 20 y 55 años. No obstante, las fuentes difieren en este punto: para Manero las edades más afectadas son las comprendidas entre los 21 y los 30 años para los varones, tanto por el número de invasiones como de defunciones que se registran en su seno, puesto que a su criterio predisponen a la afección «el temperamento sanguineo, el régimen alimenticio de sustancias animales, el exceso de bebidas alcohólicas y los placeres venéreos; la fatiga y las emociones fuertes"; ${ }^{18}$ para nosotros, tras el ordenamiento de los datos parro-

17 Cardoso, Liro, F. S., Pérez Brigoli, H., "Los métodos de la Historia», Barcelona, 1976, páginas 105-113.

18 MANERo, E., "La fiebre amarilla...", Alicante, 1879, p. 31. 
quiales, los grupos de edad más afectados alcanzan a individuos más maduros, aunque sin llegar a alcanzar nunca el período de vejez en que la mortalidad epidémica desciende notablemente en relación al total. Como vemos en la gráfica, las cotas más altas de la incidencia de la mortalidad se da en los grupos de edad de 30-34 años y 45-49, y a partir de las cohortes escalonadas que encontramos desde los 55 años, observamos que en dichos grupos de edad se da menos del $3 \%$ de la mortalidad total.

En el sexo femenino también se producen invasiones y muertes pero con una intensidad menor que en su opuesto: $189 \% 0$ de invasiones frente a un $720 \%$, en los varones, sin incluir en los porcentajes a niños y niñas de hasta diez años por no existir distinción de sexos en la estadística.

En lo referente a los efectos de la mortalidad en los grupos de edad del sexo femenino, observamos que las cifras siempre se mueven por debajo con relación a sus homónimos masculinos, ya que en casi ningún grupo de edad la mortalidad femenina supera a la masculina, si nos atenemos a las fuentes parroquiales, mientras que según los datos de Manero la mortalidad masculina supera en todo momento a la femenina. Otra consideración a hacer es la referente a la proporcionalidad que se detecta entre ambas mortalidades, pues también los grupos de edad más afectados en el sexo femenino son los de edad adulta entre 21 y 55 años, disminuyendo notablemente la incidencia de la muerte en los grupos más jóvenes, hasta los 20 años, y más ancianos, a partir de los 55 años. También para Manero, el grupo más afectado, como en el caso de los varones, sería el que va entre los 21 y los 30 años, disminuyendo los efectos de la mortalidad a partir de éste. Si nos ceñimos a los datos parroquiales, la incidencia de la muerte es desigual en las distintas cohortes, pero siguiendo la tendencia que observamos para los efectivos masculinos, esto es: mayor grado de mortalidad en los grupos de edad comprendidos ente los 30 y 55 años, disminuyendo más tarde en las cohortes de edad más avanzadas; sin embargo, en muchos grupos de edad que se jalonan a partir de los 55 años, la mortalidad en el sexo femenino es mayor que en el masculino, invirtiéndose levemente la tendencia general de mayor mortalidad masculina, no obstante, este hecho no sucede si nos atenemos a los datos de Manero, en los que la mortalidad masculina 
prevalece en general y en todos y cada uno de los grupos de edad.

En resumen, y como conclusión más importante, tenemos que entresacar el hecho de que la incidencia de la muerte es mayor para los efectivos varones del vecindario, siendo particularmente destructiva para los hombres que forman parte de grupos de edad adulta y, en concreto, en edad laboral, lo que trae como consecuencia una pérdida masiva de mano de obra para las actividades económicas al fallecer 1.082 individuos en edad laboral, y sólo 327 si nos atenemos a las fuentes parroquiales.

De la misma forma que la muerte ha producido una selección sexual, observamos, por lo menos, dos tipos más de diferencias ante la muerte: las desigualdades geográficas y las desigualdades sociales. Vamos a tratar de ilustrar estos hechos, que aunque han sido mencionados de pasada, merecen un análisis más pormenorizado.

En lo que respecta a las primeras, debemos resaltar que la fiebre amarilla es una enfermedad endémica entre los puntos situados entre los paralelos $30^{\circ}$ y $40^{\circ}$, en particular en la América Central y Meridional, y en Africa Occidental y Ecuatorial. De vez en cuando ha invadido el sur de Europa y en concreto el Levante Peninsular, lugar ideal para el mosquito Aedes aegypty, transmisor de la enfermedad. El tifus icteroides jamás se ha presentado más allá de los $48^{\circ}$ de latitud Norte, ni en puntos que excediesen de 170 metros sobre el nivel del mar. Alicante está situada por debajo del paralelo $48^{\circ}$, concretamente se encuentra la ciudad entre los $38^{\circ} 2^{\prime} 4^{\prime \prime}$ de latitud Norte y al nivel del mar. Por otra parte, Manero da como causas de esta enfermedad estas tres: existencia de focos de infección, de calor y humedad en el ambiente. ${ }^{20}$ Que Alicante contiene un foco de infección ya lo hemos anotado, pero también tenemos que decir que Alicante durante el período epidémico presentaba unas temperaturas máximas superiores a $21^{\circ} \mathrm{C}$ por encima de las cuales el Aedes aegypty se desarrolla en magníficas condiciones, y lo que es peor también se constata la existencia de una alta humedad relativa en la atmósfera ya que la virulencia de la epidemia aumenta

MANERO, E., "Topografía médica...", Alicante, 1883, p. 386 y ss. 
con el ascenso de la humedad relativa del aire. Cuando las temperaturas se van haciendo más bajas con el avance del invierno la epidemia va perdiendo fuerza. frenada a la vez por las medidas higiénicas y sanitaras puestas en práctica.

Está claro que la ciudad de Alicante por su latitud, altitud y circunstancias meteorológicas teóricamente era uno de los lugares idóneos para el desarrollo de una epidemia de este tipo; aparte de poseer otro tipo de condicionamientos económicos, sociales, etc., que hacen posible una mayor virulencia en la enfermedad.

Ahora bien, la fiebre amarilla ataca, según los indicios, de forma desigual ya se trate del núcleo urbano o de las partidas rurales que componen el municipio, ya que la fiebre amarilla se manifiesta en su forma urbana y no se presenta en lugares que carecen de la típica estructura ciudadana y presentan un poblamiento menos concentrado, por no decir disperso. De nuevo, sabemos que el contagio no hace acto de presencia en las partidas rurales del municipio por el testimonio de Manero: "La fiebre amarilla difundida por la población toda, sin excepción de barrio ni calle, perdía su influencia transmisora y epidémica a dos kilómetros de distancia en cualquier sentido que fuese; así explicamos los numerosos ejemplos de enfermos que emigraron a otros lugares o país, donde terminó la enfermedad en mal o en bien, pero sin contaminar a las personas vecinas, ni a las que se relacionaban de modo más directo. La infección fuera de Alicante quedó limitada a los individuos que fueron invadidos dentro de la ciudad, sin ulteriores consecuencias para sus acompañantes". ${ }^{21}$ De la misma forma, en el interior de la ciudad debió existir un desigual reparto en los índices de morbilidad y mortalidad ya que la muerte ha hecho una selección en razón de la ubicación geográfica de los individuos.

Como ha estudiado V. PÉREz MOREDA para la España del interior: "La mortalidad diferencial muestra todo el rigor de las desigualdades sociales con motivo de la crisis de mortalidad más agudas". ${ }^{22}$ Si las crisis de subsistencias afectan casi exclusiva-

21

22

MANero, E., "Topografía médica...", Alicante, 1883, p. 392.

Pérez Moreda, V., "Las crisis de mortalidad en la España del interior", Madrid, 1980, pp. 218-231. 
mente a las clases menos pudientes de la sociedad, las crisis epidémicas muestran el mismo fenómeno ya que la capacidad de reacción para afrontar la crisis se encontraba casi por completo en manos de las clases privilegiadas. Frente a una medicina de ricos encontramos una medicina de pobres: prácticas médicas cuyas diferencias se agrandan por las diferencias económicas y culturales que separan a las clases sociales, Manero da cuenta de esa diferencia y añade a ésta un grado de confianza popular con los médicos: "En los primeros días de la epidemia, las gentes miraban con singular recelo cualquier decisión en contra de la constitución reinante, y los médicos eran objeto y blanco de su animadversión y amenaza. Atribuyendo el excesivo número de defunciones al afán de exterminar la epidemia en corto plazo envenenando a los invadidos, llamaban al medicamento el jicarazo, y muchísimos se obstinaban en no tomarlo, al paso que preferian ser asistidos por curanderos y barberos hasta que aparecía la gravedad extrema. Ello es lo cierto, que un buen número de víctimas arrastró la Parca hallándolas sin defensa, abandonadas a su pobre desgracia y torpe conducta...". ${ }^{23}$ De esta forma, la muerte arrastró consigo a muchos individuos de las clases más débiles económica y culturalmente.

La huida constituía un reflejo de clase ante la crisis pues, ante la proximidad del contagio, era puesta en práctica con prontitud y celeridad por las clases privilegiadas, sin tener que llegar a los extremos de desesperación del resto del vecindario: «EI 15 de septiembre (...) fue la voz de alerta (...) cundió el pánico y el terror entre las gentes (...) y en menos de diez dias la ciudad se despobló y sólo quedaron en ella los pobres y algunas otras personas, que, víctimas siempre de la caridad, no habían querido dejar a sus hermanos". ${ }^{24}$ Entre las personas que abandonaban la ciudad se encontraban algunos individuos que no dudaban en abandonar cargos públicos: el 21 de octubre, la Corporación Municipal envía un oficio al gobernador civil de la provincia "consultándole si serán o no válidos los acuerdos del Ayuntamiento en las actuales circunstancias, pues la ausencia de algunos seAlicante, 7 de diciembre de 1870. 
ñores concejales y la enfermedad de otros impide la celebración de sesiones, por no reunirse mayoría según marca la Ley". ${ }^{25} \mathrm{De}$ esta manera, frente a actitudes de altruismo y entrega encontramos posturas egoístas y de abandono de la población en jornadas aflictivas; así, el 28 de octubre en sesión del Cabildo Municipal se efectúa la sesión instalatoria del nuevo Ayuntamiento, en vista de la ausencia de mayoría en el anterior, "ya que seis ediles habían sido invadidos y diez ediles habían abándonado la población en las tristes y aflictivas circunstancias en que se encontraban, ${ }^{26}$ siendo destituidos en dicha sesión; pero, también encontramos deserciones en otros cargos públicos, la "República Española» habla de ellas ${ }^{27}$ concretamente de un médico del Hospital Civil, dejando partes firmados sin novedad, y del administrador de los establecimientos de beneficencia.

El comportamiento social de huida en tiempos de epidemia nos parece enormemente significativo; pudiéndose mostrar una relación casi constante entre pobreza, hambre y enfermedad, haciendo cierta la observación de J. Nadal de que "Las enfermedades infecciosas se presentan en el siglo XIX como enfermedades sociales típicas". ${ }^{28}$

\subsection{Medidas higiénicas y sanitarias de la administración}

Seis días después de declarado sucio el puerto barcelonés, el 14 de septiembre de 1870 tiene lugar en el Ayuntamiento de la ciudad de Alicante una sesión extraordinaria presidida por el gobernador civil de la provincia, don José Gabriel Balcázar, y cuyo objetivo era el de allegar recursos debido a que el estado sanitario de la ciudad no era muy satisfactorio; por ello el municipio "debía precaverse (...) si por desgracia se comunicase a esta capital la enfermedad allí (en Barcelona) existente" ${ }^{29}$ hecho que es posible que se produzca puesto que el gobernador civil de la

Registro salida de documentos del Ayuntamiento de Alicante, oficio 1.051, 1870.

A. M. A., Libro de Sesiones del Cabildo Municipal, 1870.

Diario "La Revolución", Alicante, 11 de octubre 1870.

NADAL, J., "La población española", Barcelona, 1973, p. 166.

A. M. A., "Libro de sesiones del Cabildo Municipal", Alicante, 1870. 
provincia, informa que ya había reunido a la Junta de Sanidad, la cual había acordado una serie de medidas que se justificaban por los dos casos de carácter sospechoso ocurridos el dia anterior. Después de una discusión, se acordó por unanimidad el nombramiento de una comisión destinada a abrir una suscripción voluntaria por parte de los contribuyentes, cuyos donativos les serian reintegrados posteriormente del fondo de calamidades públicas.

El día 22 de septiembre se crea una Junta Municipal de Sanidad de la que formaban parte dos médicos (José Antonio Seguí y Vicente García Soler), un farmacéutico (José Carlos Bellido), un veterinario (José Such y Gadea) y tres vecinos (Antonio Guillén López, José Mira y Mariano Ibarra).

El 29 del mismo mes, Bartolomé Pons da lectura en la sesión del Cabildo a una proposición que adquirirá, ${ }^{30}$ mediante su publicación en el diario republicano-federal, una difusión extraordinaria. En ella se da cuenta del estado anormal, de crisis y de paralización en que se encuentra la ciudad y cuya responsabilidad recae, según él y ante la marcha de la Diputación Provincial a Villena, ${ }^{31}$ en el Ayuntamiento ya que ha recibido sus poderes del pueblo y por ello ha de acudir a remediar la crisis con medidas enérgicas, atendiendo al estado anormal en que se encuentra la población, que haciendo caso de los rumores que circulan sobre su estado sanitario se halla perturbada y los trabajos paralizados con la consiguiente desesperación de la clase trabajadora.

El 1 de octubre se celebra una sesión extraordinaria del Cabildo, que se trató de efectuar el día anterior en que no concurrieron suficiente número de concejales para formar mayoría; en ella la Comisión Municipal elegida al efecto tenía que formular el dictamen acerca de la proposición presentada por B. Pons y

30 A. M. A., "Libro de sesiones...", Alicante, 1870 y Diario "La Revolución”, Alicante, 5 de octubre 1870 .

31 No tenemos noticia exacta del traslado de la Diputación Provincial a Villena, pero éste se debió producir por la inminencia de la epidemia. Lo que si se sabe es la fecha del regreso: a partir del 27 de diciembre. B. O. P., Alicante, 27 de diciembre de 1870. 
con el fin de "procurarse medios prontos y bastantes para hacer frente a la fiebre amarilla", reconociéndose más adelante "que no nos hayamos ocupado de este asunto de tan vital interés, desde 15 o más dias ha que apareció la epidemia (...) que aflige a nuestros hermanos de Barcelona, siempre es tiempo sin embargo para hacer bien". ${ }^{32}$ A continuación se disponen las siguientes medidas: Pedir al Gobierno un auxilio del fondo de calamidades públicas, aun cuando sea en calidad de reintegro; dirigir a las cortes una petición para que se abonen sus haberes a las clases pasivas; pedir a las autoridades civil y económica de la provincia y al mismo Gobierno que se aumente la consignación en la fábrica de tabacos, "único auxilio con que cuentan hoy en esta capital las clases trabajadoras»; ${ }^{33}$ que se efectúe un reparto entre los contribuyentes de hasta el 25 por cien de lo que pagan al Estado y además un escudo por vecino para calamidades públicas, según autoriza la ley; emplear el mayor número de jornaleros en el arreglo de calles y aceras con los arbitrios conseguidos; excitar el patriotismo de las clases acomodadas para que reformen sus edificios a fin de dar trabajo a los artesanos y por último establecer un anticipo voluntario y reintegrable con un interés del 6 por cien y amortización semestral.

El 3 de octubre, antes de declararse sucio el puerto, se reconoce tácitamente la existencia del contagio, ya que en la sesión de aquel día se nombraron comisiones de distrito para investigar a las familias pobres que tuvieran enfermos; se aumentó el número de médicos titulares de dos a cinco por el tiempo de duración de la epidemia; se contrató un carruaje para conducir enfermos al Hospital Provisional y se aumentó el número de barrenderos para garantizar una escrupulosa limpieza en las vías públicas; se dieron amplios poderes al señor alcalde para que se puedan nombrar el número necesario de practicantes y se agregaron tres concejales a la Comisión de Mercados con el fin de extremar la vigilancia. ${ }^{34}$

32 A. M. A., "Libro de sesiones...", Alicante, 1870.

33 A. M. A., "Libro de sesiones...", Alicante, 1870.

34 A. M. A., "Libro de sesiones...", Alicante, 1870. 
En estas fechas se efectuaron una serie de medidas higiénicas en la ciudad: se ordenó la apertura de un lazareto de expurgo incluso en fecha anterior a la apertura del Lazareto de Sevilla para las procedencias de Cataluña, lo cual es sintomático ${ }^{35}$ y la creación de un cordón sanitario; se expidieron oficios a las posadas para que se hiciera en ellas una limpieza diaria de las cuadras con agua clorurada al igual que en los almacenes comerciales; se ordenó que se retiraran de los establecimientos alimentos en mal estado, se instaló un Hospital Provisional con el personal y material correspondiente. ${ }^{36}$

A partir del 5 de octubre, en que se declara sucio el puerto alicantino, hasta el 28 del mismo mes, el Cabildo Municipal ve como se reduce el número de ediles que asisten a las sesiones ya que seis concejales han sido invadidos por la enfermedad y once han abandonado el cargo ${ }^{37}$ que los electores les habian confiado hasta el punto que el consejo no reúne la mayoría necesaria para celebrar sus reuniones al permanecer únicamente diez concejales en su puesto. De esta forma se llega al 28 de octubre, fecha en que tiene lugar la sesión instalatoria del nuevo Cabildo bajo la presidencia del delegado del Gobierno, señor Alcalá Zamora, que venía a informarse acerca del estado de la población y a aportar una ayuda estatal de 10.000 pesetas, manifestando la determinación de constituir el nuevo Ayuntamiento cubriendo todas las vacantes con personas que habian pertenecido anteriormente a la Corporación para que ésta pudiera funcionar bajo la presidencia honoraria de Eugenio Barrejón al haber caído enfermo su anterior presidente, Francisco García López, que morirá poco después. ${ }^{38}$ Durante el período anterior a la instalación de este Cabildo se constituye la Junta Central de Socorros con objeto de arbitrar recursos para distribuirlos entre los enfermos y necesitados ya que los fondos gubernamentales no

Diario "La Revolución", Alicante, 24 septiembre 1870.

A. M. A., Registro Gral., salida documentos del Ayuntamiento, ordenes 965, 968, 970, Alicante, 1870.

Sólo tenemos noticias de uno de ellos, Juan Such que ha ido a Polop a "tranquilizar a su familia".

A. M. A., "Libro de sesiones...", Alicante, 1870. 
habian sido entregados aún (10 de octubre); más tarde se acuerda el traslado de la Reliquia de la Santa Faz a la capital pero "con el mayor sigilo para que no se aperciba el vecindario" ${ }^{39}$. Sin embargo la situación parecía deteriorarse por momentos como presumía Maisonnave en un telegrama al Ministerio de Gobernación "Estado sanitario tristísimo, situación comprometida. Invasiones de fiebre amarilla aumentan. Defunciones crecen; falta trabajo absoluta; emigración clases acomodadas completa. Autoridades municipal y provincial en la mayor inacción (...). Multitud de enfermos abandonados a la caridad privada (...). Gobernador desprestigiado (...). Ayuntamiento indiferente al peligro (..). Presiento graves conflictos". ${ }^{40}$

Constituido ya el nuevo cabildo municipal, el 6 de noviembre se crea un presupuesto extraordinario para la ejecución de las obras proyectadas durante esta época de paralización, dicho presupuesto ascendia a 25.525 pesetas y las obras que se habían de realizar contribuían a mejorar la higiene de la ciudad. Estos trabajos eran, entre otros: Niveles de escombros existentes en el foso de la muralla del barrio de San Francisco; formación de cloacas en Arrabal Roig; cubrimiento de aguas del barranco de la Goteta que surtían al matadero; construcción de compuertas en las alcantarillas del puerto; conclusión hasta el mar de la cloaca del Postiguet y levantamiento de tapias y zanjas en el cementerio de San Blas. Los reunidos concluyen diciendo que "si bien el municipio no se encuentra con recursos para hacer frente a dichas obras, todas ellas podrán al par de dar trabajo a la clase pobre ser de mucha utilidad pública porque en todas ellas se basa directamente la higiene pública». Finalmente el acuerdo se remitió a la aprobación superior. En esta fecha los gastos de la epidemia ascendían a 39.255 pesetas que quedaron consignadas dentro de otro presupuesto extraordinario. ${ }^{41}$

El 16 de noviembre se aprobaron y publicaron unas normas sanitarias elaboradas por la Junta Provincial de Sanidad estable-

39 A. M. A., "Libro de sesiones...", Alicante, 1870, 10 y 24 de octubre.

40 Diario "La Revolución", Alicante, 27 de octubre.

41 A. M. A., "Libro de sesiones...", Alicante, 6 de noviembre de 1870. 
ciendo la necesidad de fumigación en las casas que estuviesen deshabitadas en que hubiese habido uno o más enfermos, no pudiendo ser ocupadas de nuevo hasta transcurridos ocho días después de su fumigación. Esta norma se aplicaría igualmente en las casas que hubiesen permanecido cerradas desde el comienzo del contagio, designando sus dueños a personas que en su representación facilitasen a la Comisión encargada de las fumigaciones, ésta proveería de una certificación que acreditase la fumigación de las viviendas, prohibiéndose la entrada a la ciudad de toda persona que careciera de este documento. Los gastos de este servicio se abonarian de acuerdo con la posición personal de los propietarios. ${ }^{42}$

Paralelamente, desde el Gobierno Civil se lanza otro bando de la Junta Provincial de Sanidad para tratar de impedir la inmigración precipitada sin las debidas precauciones, ${ }^{43}$ puesto que algunas personas son invadidas a su regreso. ${ }^{44}$

En la sesión del Cabildo Municipal del 26 de noviembre y en vista que la enfermedad empieza a declinar en gran medida se suprime el lazareto de espurgo y se suaviza el cordón sanitario que ha de evitar únicamente los equipajes de los vecinos que no presenten el certificado de fumigación. ${ }^{45}$ De esta forma paulatina, pero sostenida la fiebre amarilla va perdiendo fuerza hasta que el dia 12 de diciembre se convoca desde el Ayuntamiento un solemne "Te Deum" en acción de gracias por la desaparición del mal; este acto se celebraría a las 11 de la mañana del día siguiente en la Colegiata de San Nicolás con la asistencia de las autoridades civiles y militares. El 17 de diciembre se dan por concluidos los trabajos del Hospital Provisional ${ }^{46}$ y un poco más tarde se declara limpio el puerto alicantino.

Por lo que antecede se puede comprender la desconfianza del vecindario ante las autoridades pues las medidas sanitarias e higiénicas comienzan a emprenderse avanzada la epidemia.

\footnotetext{
42 A. M. A., "Libro de sesiones...", Alicante, 16 de noviembre de 1870.

43 B. O. P., Alicante, 26 noviembre.

44 Diario "La Revolución", Alicante, 24 de noviembre de 1870.

45 A. M. A., "Libro de sesiones...", Alicante, 1870.

46 A. M. A., "Libro de sesiones...", Alicante, 1870.
} 
Antes se constataban las protestas de Bartolomé Pons qu aducía que el Consejo Municipal no se ocupaba del problema, sabiendo que existían numerosos casos de contagio en Barcelona, puerto en permanente comunicación con Alicante. También tenemos indicios de que la Diputación Provincial presentaba deficiencias en su normal funcionamiento pues "varios empleados de la misma corporación han abandonado sus destinos y los señores diputados no tienen a bien reunirsen; ${ }^{47}$ este inconveniente se resolverá más tarde con el traslado de la Diputación a Villena, pero no obstante durante cierto tiempo se creó una situación anómala en la corporación provincial y, como señalábamos, en la municipal al abandonar gran número de concejales sus puestos en los momentos más críticos.

No sería justo pasar por alto la actitud de otras autoridades y de los médicos que hicieron cuanto pudieron para vencer la fiebre amarilla, cuyo antídoto por medio de vacunación no fue descubierto hasta 1891 por el médico cubano Carlos Finlay, por lo que hay que reconocer que los medios para atajarla no fueron óptimos.

\subsection{Medios de financiación de la epidemia}

Habría que resaltar que los medios de financiación para paliar los efectos de la epidemia fueron escasos por la dificultad de encontrarlos, y supeditados en gran medida a la caridad pública y a los préstamos de particulares. Al presentar el municipio en su presupuesto ordinario un déficit bastante elevado, ${ }^{48}$ no pudieron hacer frente en algunos momentos a los gastos derivados de la epidemia hasta el punto de enviar una carta a los medios de comunicación exhortando la caridad de los ciudadanos: "Alicante se pierde, tenémos que salvar a Alicante (...) El Ayuntamiento de Alicante pida a Ud. una limosna para las víctimas de la miserian. ${ }^{49}$ Fundamentalmente los gastos para paliar la epidemia procedieron de tres fuentes: Primeramente del Gobierno de 
la nación que envió del fondo de calamidades públicas con su delegado Alcalá Zamora una ayuda de 10.000 pesetas entregadas en la sesión del Cabildo del 28 de octubre y más tarde una suma de 15.000 pesetas, de ellas 5.000 distribuidas a partir del Ayuntamiento, y del total 13.000 pesetas fueron a financiar los gastos sanitarios y las restantes 2.000 fueron a parar a manos de los pobres. ${ }^{50}$ Una suma más importante aporta la Junta Central de Socorros, asociación caritativa instituida, como veíamos, para allegar recursos y distribuirlos entre los enfermos necesitados de la ciudad; hasta el 7 de diciembre se habían repartido mediante esta asociación 25.836 pesetas distribuidas a través de 44.781 bonos. ${ }^{51}$ No obstante, la mayor cifra de dinero la encontramos en el presupuesto extraordinario del Ayuntamiento alicantino que asciende a 39.255 pesetas, ${ }^{52}$ parte de las cuales procedían de una suscripción de donantes voluntarios al municipio, otra de un impuesto a los contribuyentes del $25 \%$ de lo que recaudaba el Estado y de otro de un escudo por vecino para calamidades públicas. A esta cifra, hemos de sumar la de 25.525 pesetas provenientes de otro presupuesto extraordinario con el fin de realizar obras para mejorar las condiciones higiénicas de la ciudad y dar trabajo a los jornaleros en paro.

Tampoco faltan noticias acerca de la solidaridad de vecinos de otros pueblos que, como en el caso de Torrevieja, Hellín y Agramón, envían donativos para aliviar, en lo posible, los sufrimientos de los indigentes de Alicante, ${ }^{53} \mathrm{ni}$ por supuesto, falta la caridad de los particulares como los ocupantes del vapor "Vigilante» ${ }^{54}$ y Salvador Lacy que envía al Ayuntamiento "un billete de la sucursal del Banco de Españam. ${ }^{55}$ Hay que señalar, por último, la destacada labor que, en este sentido, ejerce "El Impar-

Diario "La Revolución", Alicante, 11 de noviembre de 1870. Registro de salida documentos del Ayuntamiento, 11 de noviembre de 1870. Diario "La Revoiución", Alicante, 8 de octubre, 7 de diciembre.

A. M. A., "Libro de sesiones...", Alicante, 6 noviembre de 1870.

Diario "La Revolución", Alicante, 11 y 20 de noviembre de 1870.

Diario "La Revolución", Alicante, 11 de octubre de 1870.

A. M. A., Registro Oficial de salida documentos Ayuntamiento de Alicante, oficio 1.872 , año 1870 . 
cial» que consigue a través de una suscripción de sus lectores 7.643 pesetas con destino a los pobres. ${ }^{56}$

Como vemos, los gastos ocasionados por la epidemia no bajaron de 123.571 pesetas, según nuestros insuficientes datos, pudiendo ser mucho más; de todas maneras es ésta una cifra importante si tenemos en cuenta que el Ayuntamiento ha ingresado ese año 35.792 pesetas (hasta el 21 de marzo y para su presupuesto ordinario) y ha gastado 137.682 pesetas. ${ }^{57}$ A destacar, pues, la incapacidad de la Administración, en sus tres vertientes: central, provincial y municipal, para solventar con sus propios medios los gastos que acarrea una catástrofe de este tipo; la necesidad de recurrir a dinero de particulares ya sea a nivel de contribución extraordinaria o exhortando la caridad pública como medios de financiación de los gastos acarreados por una epidemia. Por último, destacar el papel de asociaciones ocasionales: Junta de Socorros, diario "El Imparcial», para solventar en lo posible las deficiencias de la Administración.

(Ver siguiente cuadro).

56 Diario "La Revolución", Alicante, 5 de octubre de 1870 y ss.

57 A. M. A., "Libro de sesiones...", Alicante, 1870. 


\section{CUADRO 1:}

Número de defunciones a causa de la epidemia de fiebre amarilla de 1870 , según los libros de enterramientos de las Parroquias de San Nicolás y Santa María de Alicante:

\begin{tabular}{ccccccc} 
AÑOS & HOMBRES & $\%$ & MUJERES & $\%$ & TOTALES & \multicolumn{1}{c}{$\%$} \\
\hline $0-4$ & 8 & 1,40 & 1 & 0,19 & 9 & 1,59 \\
$5-9$ & 4 & 0,70 & 1 & 0,19 & 9 & 1,59 \\
$10-14$ & 6 & 1,05 & 7 & 1,22 & 13 & 2,27 \\
$15-19$ & 15 & 2,61 & 12 & 2,10 & 27 & 4,71 \\
$20-24$ & 31 & 5,41 & 20 & 3,46 & 51 & 8,90 \\
$25-29$ & 26 & 4,54 & 11 & 1,91 & 37 & 6,45 \\
$30-34$ & 47 & 8,20 & 24 & 4,19 & 71 & 12,39 \\
$35-39$ & 35 & 6,10 & 18 & 3,14 & 53 & 9,24 \\
$40-44$ & 41 & 7,16 & 26 & 4,54 & 67 & 11,70 \\
$45-49$ & 47 & 8,20 & 22 & 3,84 & 69 & 12,04 \\
$50-54$ & 44 & 7,68 & 32 & 5,58 & 76 & 13,26 \\
$55-59$ & 16 & 2,80 & 17 & 2,97 & 33 & 5,77 \\
$60-64$ & 15 & 2,61 & 11 & 1,92 & 26 & 4,53 \\
$65-69$ & 6 & 1,05 & 8 & 1,40 & 14 & 2,45 \\
$70-74$ & 9 & 1,57 & 6 & 1,05 & 15 & 2,64 \\
+75 & 0 & - & 5 & 0,86 & 5 & 0,86 \\
\hline TOTALES & 349 & 60,90 & 224 & 39,10 & 573 & 100,00
\end{tabular}




\section{CUADRO 2:}

Número de defunciones a causa de la epidemia de fiebre amarilla de 1870 , segun E. MANERO.

\begin{tabular}{rcrcrrr} 
AÑOS & HOMBRES & \multicolumn{1}{c}{$\%$} & MUJERES & $\%$ & TOTALES & \multicolumn{1}{c}{$\%$} \\
\hline $0-10$ & 44 & 3,19 & 26 & 1,88 & 70 & 5,07 \\
$11-20$ & 112 & 8,11 & 46 & 3,33 & 158 & 11,44 \\
$21-30$ & 536 & 38,85 & 86 & 6,23 & 622 & 45,08 \\
$31-40$ & 264 & 19,13 & 58 & 4,20 & 322 & 23,33 \\
+40 & 170 & 12,32 & 38 & 2,75 & 208 & 15,07 \\
\hline TOTALES & 1.126 & 81,60 & 254 & 18,40 & 1.380 & 100,00
\end{tabular}

FUENTE:

MANERO, E: «Topografía médica de la ciudad de Alicane, 1883. Elaboración propia.

CUADRO 3:

FUENTES DE FINANCIACION DE GASTOS ACARREADOS POR LA EPIDEMIA

\begin{tabular}{|c|c|c|c|}
\hline Fecha & Origen & Destino & $\begin{array}{l}\text { Cuantía } \\
\text { Pesetas }\end{array}$ \\
\hline \multirow{4}{*}{$\begin{array}{l}11 \text { de octubre } \\
20 \text { de octubre } \\
28 \text { de octubre }\end{array}$} & Vapor "Vigilante" & Diario Revolunción & $?$ \\
\hline & Salvador Lacy & Ayuntamiento & $?$ \\
\hline & & Ayuntamiento & 10.000 \\
\hline & Gobierno & Medidas Sanitarias & 13.000 \\
\hline \multicolumn{4}{|l|}{ Hasta } \\
\hline \multirow{3}{*}{$\begin{array}{l}11 \text { de noviembre } \\
11 \text { de noviembre } \\
20 \text { de noviembre }\end{array}$} & Suscrip.: "Imparcial» & Pobres & 7.643 \\
\hline & Vecinos Torrevieja & Pobres & 94 \\
\hline & Vecinos Hellin & Pobres & 218 \\
\hline \multirow{6}{*}{$\begin{array}{l}\text { Hasta } \\
7 \text { de diciembre }\end{array}$} & & & \\
\hline & Junta Central de & & \\
\hline & Socorros & Pobres & 25.836 \\
\hline & nario Ayuntamiento & Gastos & 39.255 \\
\hline & & Municipio & 25.525 \\
\hline & & Total & 123.571 \\
\hline
\end{tabular}


MORTALIDAD EPIDEMICA POR GRUPOS

DE EDAD Y SEXO. ALICANTE (1870)

Fuente: E. Manero

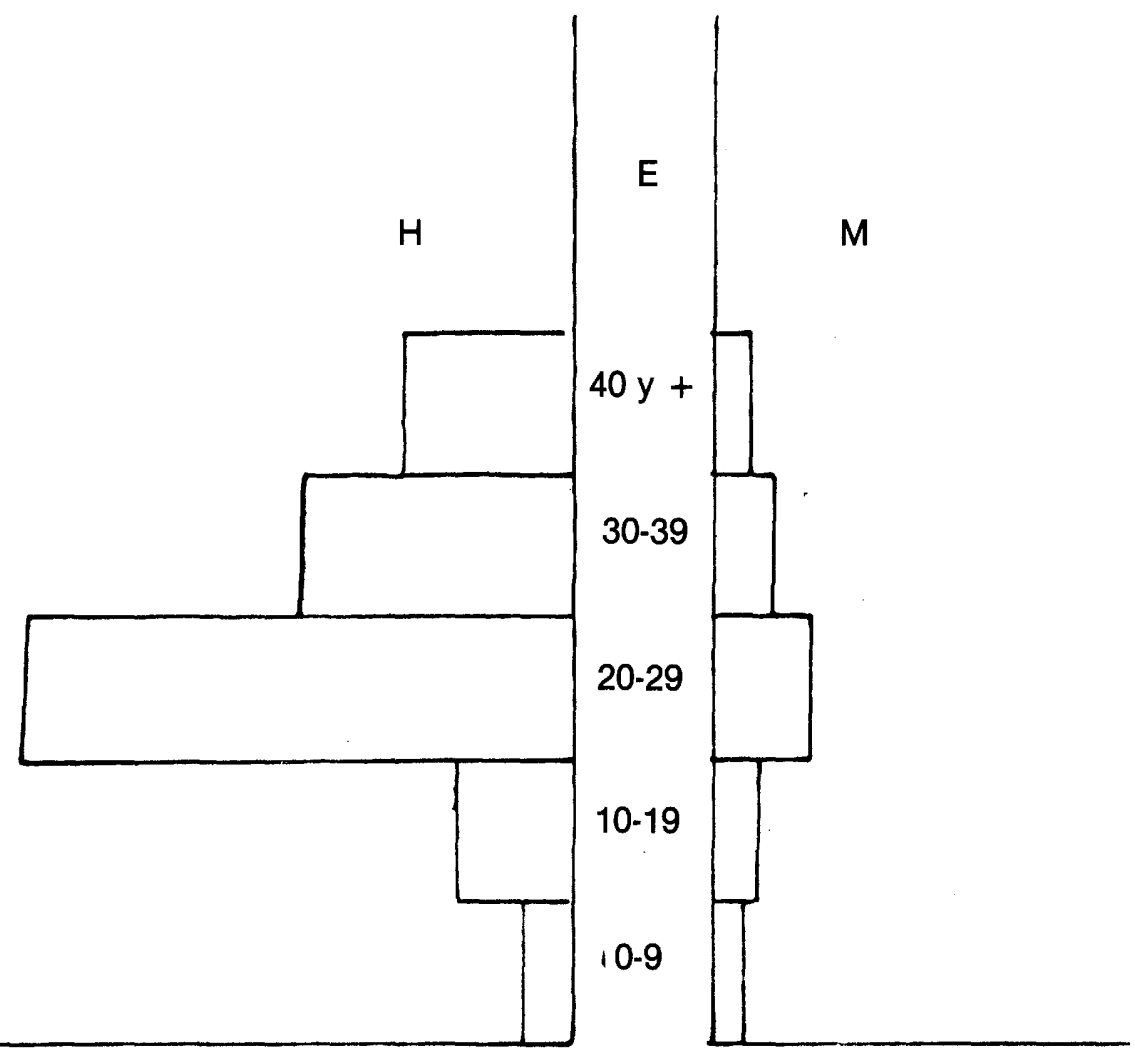




\section{MORTALIDAD EPIDEMICA POR GRUPOS DE EDAD Y SEXO. ALICANTE (1870)}

Fuentes: Libros de enterramientos San Nicolás y Santa María

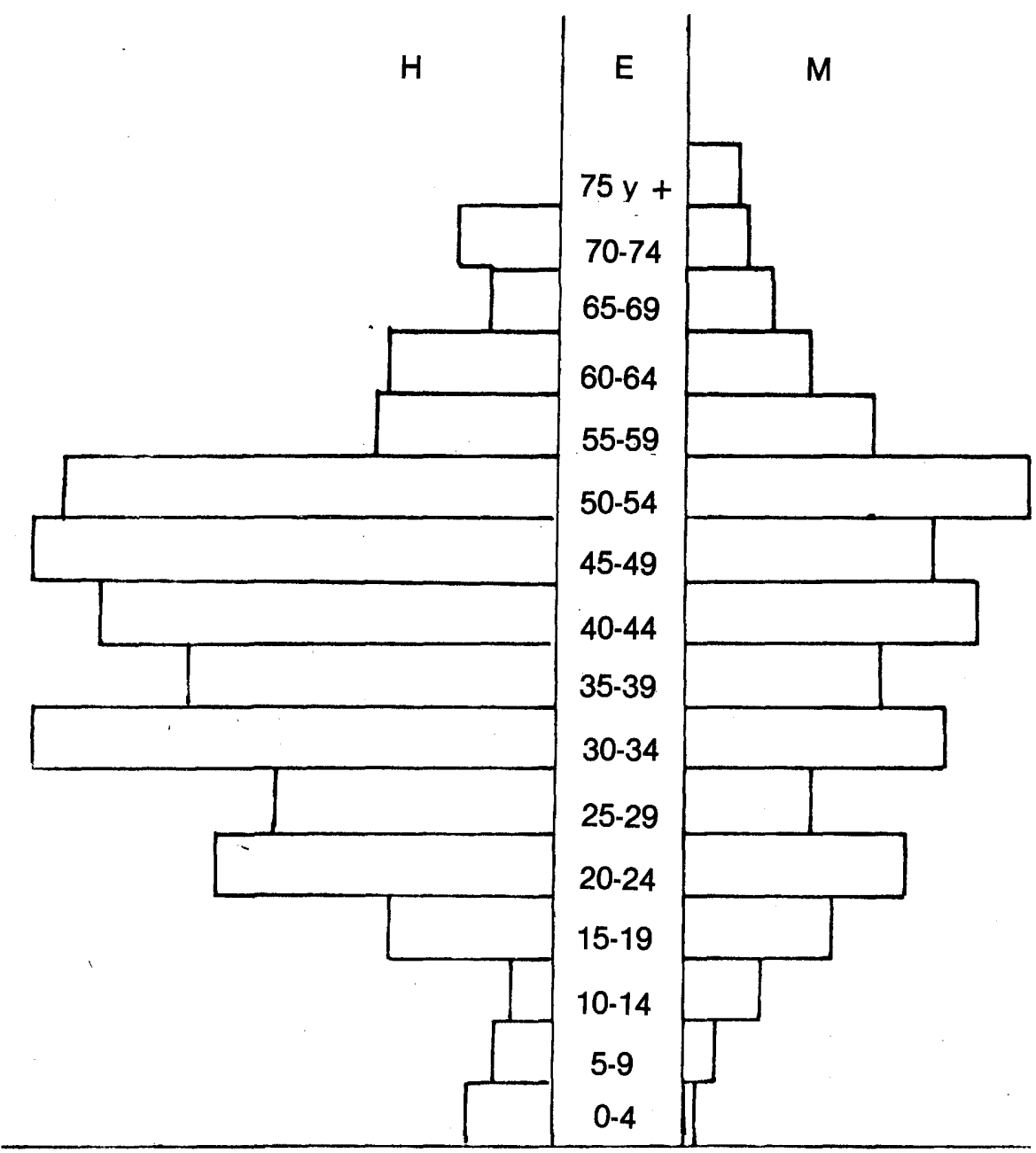

